\title{
African Materials Research Society International Conference to be Held in December
}

The African Materials Research Society (Africa-MRS) will hold its second international conference at the University of the Witwatersrand in Johannesburg, South Africa, December 8-11, 2003. The theme is "Building Partnerships for Excellence in Materials Research in Africa," in which an important focus of the conference, chaired by Yunus Ballim (University of the Witwatersrand) who is also the founding president of Africa-MRS, will be to create a forum for identifying and stimulating collaboration opportunities between countries within Africa as well as with partners on other continents. Conference participants will be encouraged to identify possible shared facilities, resources, and equipment to encourage synergy and excellence in materials research.

The conference will encourage the presentation of research work in all aspects of materials science and engineering. In particular, it will focus on the following themes:

- Processing, testing, and characterization of materials

- Infrastructure materials

- Computational aspects of materials

- Energy materials

- Polymers/composites

- Metals processing

- Raw materials beneficiation

- Materials recycling

- Materials education

The conference will combine plenary presentations with parallel sessions. Time slots will also be incorporated for freeform workshops, with subjects selected by clusters of conference participants. The conference will include technical tours of various research facilities in and around Johannesburg and an Africa-MRS meeting to adopt the constitution and elect the next executive for the society.

Africa-MRS was officially formed in December 2002 at a meeting of African scientists, researchers, and academics held in Dakar, Senegal. It was decided at this meeting to host the first conference of the society in Johannesburg. An important guiding principle in organizing the conference was that it be of high technical quality while being economical enough to encourage maximum participation by researchers in Africa.

For more information, contact Yunus Ballim, School of Civil and Environmental Engineering, University of the Witwatersrand, Private Bag 3, Wits 2050, South Africa; fax 2711-3391762; e-mail ballim@ civil.wits.ac.za; or access Web site www. wits.ac.za/AfricaMRSconf2.

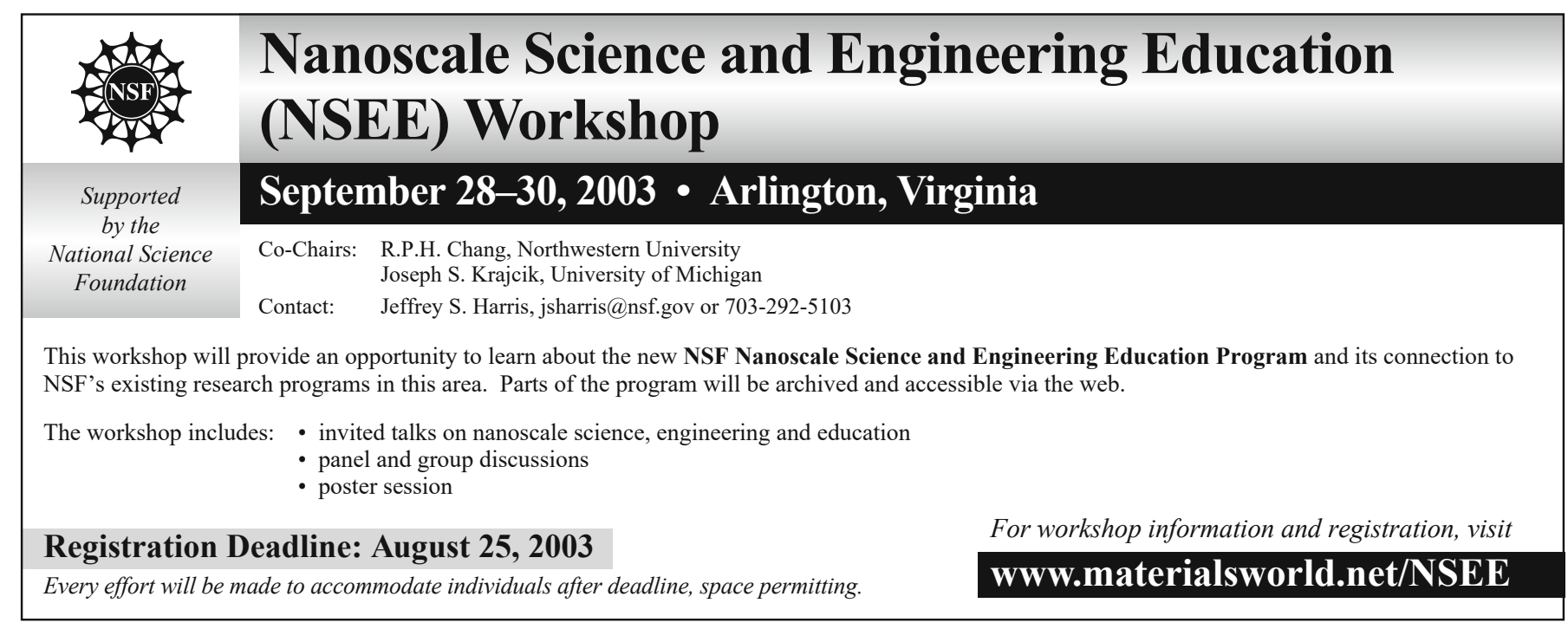

